\title{
Designing Structural Electrochemical Energy Storage Systems: A Perspective on the Role of Device Chemistry
}

\author{
Adriana M. Navarro-Suárez ${ }^{1 *}$ and Milo S. P. Shaffer ${ }^{1,2 *}$ \\ ${ }^{1}$ Department of Chemistry, Imperial College London, Molecular Sciences Research Hub, London, United Kingdom, ${ }^{2}$ Department \\ of Materials, Imperial College London, London, United Kingdom
}

Structural energy storage devices (SESDs), designed to simultaneously store electrical energy and withstand mechanical loads, offer great potential to reduce the overall system weight in applications such as automotive, aircraft, spacecraft, marine and sports equipment. The greatest improvements will come from systems that implement true multifunctional materials as fully as possible. The realization of electrochemical SESDs

OPEN ACCESS

Edited by:

Diego Cazorla-Amoros, University of Alicante, Spain

Reviewed by: Atif Javaid

University of Engineering and Technology, Pakistan

Ramiro Ruiz Rosas,

University of Malaga, Spain

*Correspondence:

Adriana M. Navarro-Suárez anavarrosuarez@gmail.com

Milo S. P. Shaffer

m.shaffer@imperial.ac.uk

Specialty section:

This article was submitted to

Electrochemistry,

a section of the journal

Frontiers in Chemistry

Received: 07 November 2021

Accepted: 03 December 2021

Published: 03 January 2022

Citation:

Navarro-Suárez AM and Shaffer MSP

(2022) Designing Structural

Electrochemical Energy Storage

Systems: A Perspective on the Role of

Device Chemistry.

Front. Chem. 9:810781.

doi: 10.3389/fchem.2021.810781 therefore requires the identification and development of suitable multifunctional structural electrodes, separators, and electrolytes. Different strategies are available depending on the class of electrochemical energy storage device and the specific chemistries selected. Here, we review existing attempts to build SESDs around carbon fiber (CF) composite electrodes, including the use of both organic and inorganic compounds to increase electrochemical performance. We consider some of the key challenges and discuss the implications for the selection of device chemistries.

Keywords: structural energy storage, carbon fibers, structural batteries, structural supercapacitors, multifunctional materials, battery chemistry

\section{INTRODUCTION}

Structural energy storage devices (SESDs), or "Structural Power" systems store electrical energy while carrying mechanical loads and have the potential to reduce vehicle weight and ease future electrification across various transport modes (Asp et al., 2019). Two broad approaches have been studied: multifunctional structures and multifunctional materials. The first combines conventional materials by embedding thin-film batteries within composite laminates or sandwich panels. Whilst there can be some synergies and particularly space saving, the structural and energy storage functions generally remain decoupled; i.e. one material bears loads, another stores energy electrochemically (Pereira et al., 2009; Thomas et al., 2013). The second approach formulates multifunctional materials that simultaneously and synergistically provide structural and electrochemical energy storage functions (Asp and Greenhalgh, 2014; Danzi et al., 2021). Both approaches have their advantages and challenges, the former offers modest savings under low mechanical loads but suffers from issues such as delamination at the device/composite interface and limited scope for synergy. The latter can potentially offer significantly greater savings in system level mass and volume but the material design is more complicated since the mechanical and electrical demands are often in conflict (Asp et al., 2015).

As discussed further below, SESDs based on fibrous composites are particularly promising. Extensive efforts have been made to identify and address the scientific challenges associated with the 


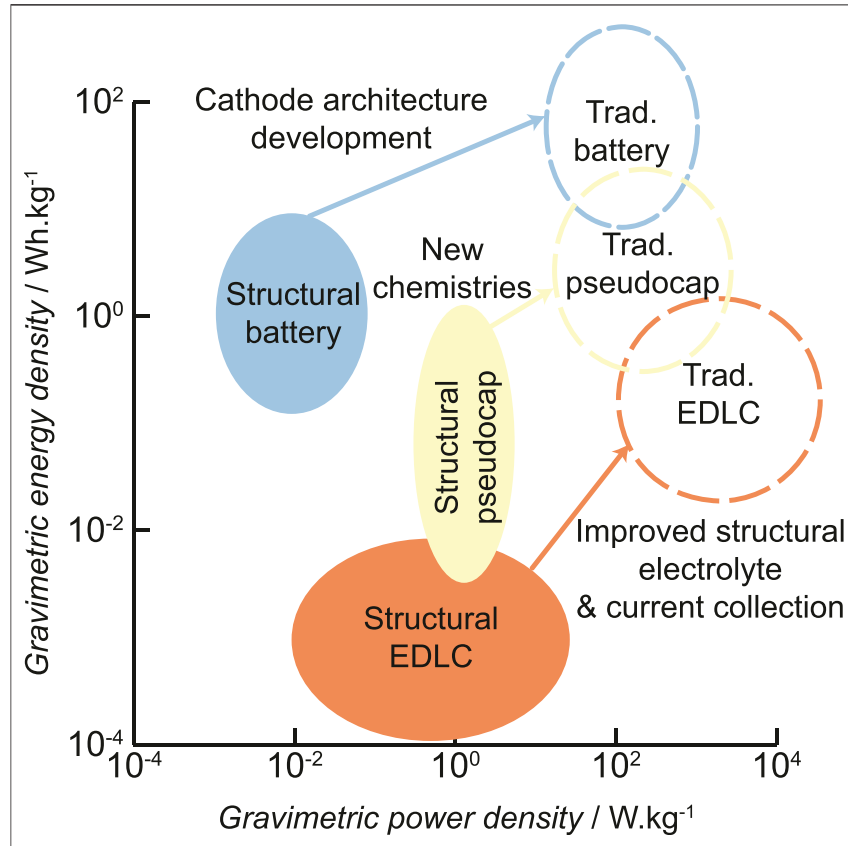

FIGURE 1 | Ragone plot of various SESDs with suggested developments to reach traditional electrochemical energy storage devices.

underlying multifunctional materials required, including structural electrodes (Liu et al., 2009; Kjell et al., 2011; Shirshova et al., 2013a), electrolytes (Snyder et al., 2007; Ihrner et al., 2017), and separators (Acauan et al., 2019; Patel et al., 2020a). Most of this research has targeted either electrical double-layer capacitors (EDLCs) or lithium-ion batteries (LIBs), leaving aside other chemistries. This focus has been driven by the cycle life/stability of EDLCs and the energy density of LIBs, but potentially misses important opportunities associated with other device chemistries and architectures, covering a wide range of energy and power densities. Novel energy storage concepts incorporating new materials and chemical processes may offer routes to circumvent some key obstacles to existing SESDs (Figure 1) and enable faster implementation in certain applications.

Wider reviews of SESDs are available, particularly describing manufacturing and engineering issues (Asp and Greenhalgh, 2014; Ferreira et al., 2016; Deka et al., 2017a; Danzi et al., 2021; Galos et al., 2021). This perspective examines the prospects for current and future device chemistries, as they may be implemented in SESDs based on fiber composites. The Current Status Section summarizes the requirements and current state-of-the-art in SESD chemistry, while the Future Needs and Prospects Section considers the selection and possible impact of alternative technologies on device performance.

\section{CURRENT STATUS}

Carbon-based materials, particularly CFs and carbon nanomaterials, are extensively used in SESDs for their electrochemical and structural performance, and low densities. Fiber composites are widely explored as the laminated architecture is common to both electrochemical and structural systems. CFs may be electrochemically active themselves, or act as framework and current collector for a multifunctional matrix packed around them. EDLCs are particularly attractive, since the energy storage process is entirely physical, depending only on the interface between electrode and electrolyte (Figures 2A,B) (Li et al., 2010; Qian et al., 2013a; Shirshova et al., 2013a; Qian et al., 2013b; Javaid et al., 2014; Shirshova et al., 2014; Westover et al., 2014; Greenhalgh et al., 2015; Javaid et al., 2016; Senokos et al., 2016; Kwon et al., 2017; Senokos et al., 2017; Shen and Zhou, 2017; Xu and Zhang, 2017; Li et al., 2018a; Chen et al., 2018; Javaid et al., 2018; Javaid and Irfan, 2018; Muralidharan et al., 2018; Senokos et al., 2018; Aderyani et al., 2019; Flouda et al., 2019a; Chen et al., 2019; Patel et al., 2019; Reece et al., 2019; Patel et al., 2020b; Rana et al., 2020; Reece et al., 2020; Sun et al., 2020; Sánchez-Romate et al., 2021; Subhani et al., 2021; Xu et al., 2021). The central advantage for SESDs, is that there is little or no change in volume, and no (re)dissolution of material, associated with the electrochemical process, minimizing stresses, and simplifying the structural design, whilst ensuring an excellent cycle life. These systems offer modest energy density, and are generally used for their power density in energy management applications, although the long lifetime, reliability, and safety means that they may be used in backup power contexts.

Energy density in EDLCs is broadly proportional to specific surface area, with the caveat that gas adsorption measurements may not reflect the electrochemically accessible regions. In general, the porosity, associated with the necessary high surface areas and electrolyte access, negatively affects mechanical properties, driving many of the efforts to exploit nanomaterials where the perfection of nanostructure may compensate for other performance losses. Whilst many promising systems have been developed, power density is also limited by the challenges of developing an effective structural electrolyte. Ionic conductivity of structural electrolyte "matrices" is usually inversely related to the mechanical properties needed to transfer load (Shirshova et al., 2013b; Ihrner et al., 2017; Schneider et al., 2019). This low ionic conductivity may dominate the equivalent series resistance of the whole device. In addition, whilst structural CFs have reasonable electrical conductivity, in larger devices/components, they may not be an adequate current collector without the addition of additional components. This constraint is more severe in EDLCs than in batteries, as the current densities are expected to be higher.

The balance of power density to energy density can be shifted by incorporating redox active constituents within the stable, high cycle life, porous framework developed for EDLCs. Many researchers have developed pseudocapacitors, by coating carbon electrodes with powders or films that can store charge through surface adsorption/desorption of ions, redox reactions with the electrolyte, or doping/undoping of the electrode materials. Modifications to improve pseudocapacitive behavior have included functional groups (Ganguly et al., 2020), conductive polymers (Benson et al., 2013; Liu et al., 2016; Shi 


\section{A Structural EDLC laminated}

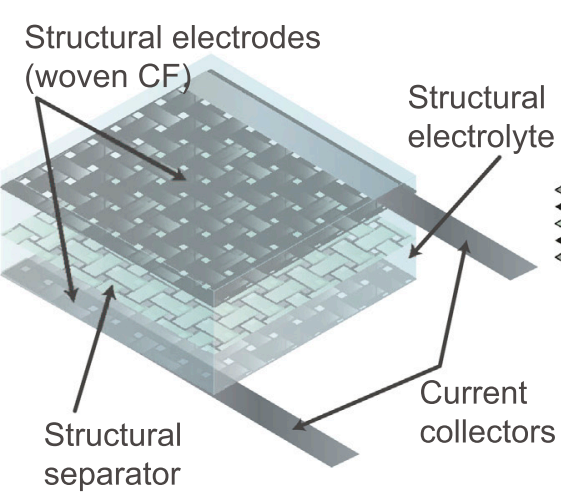

Structural electrodes (carbon veils)

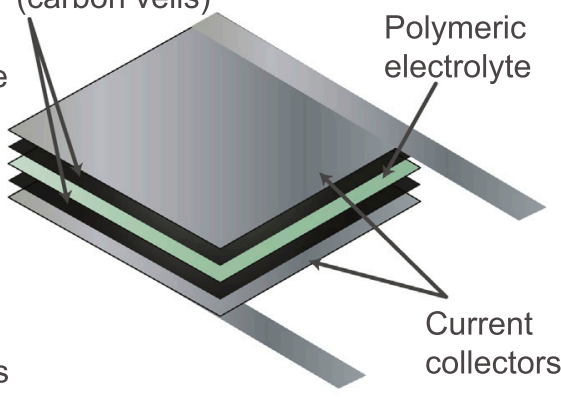

\section{Structural battery laminated}
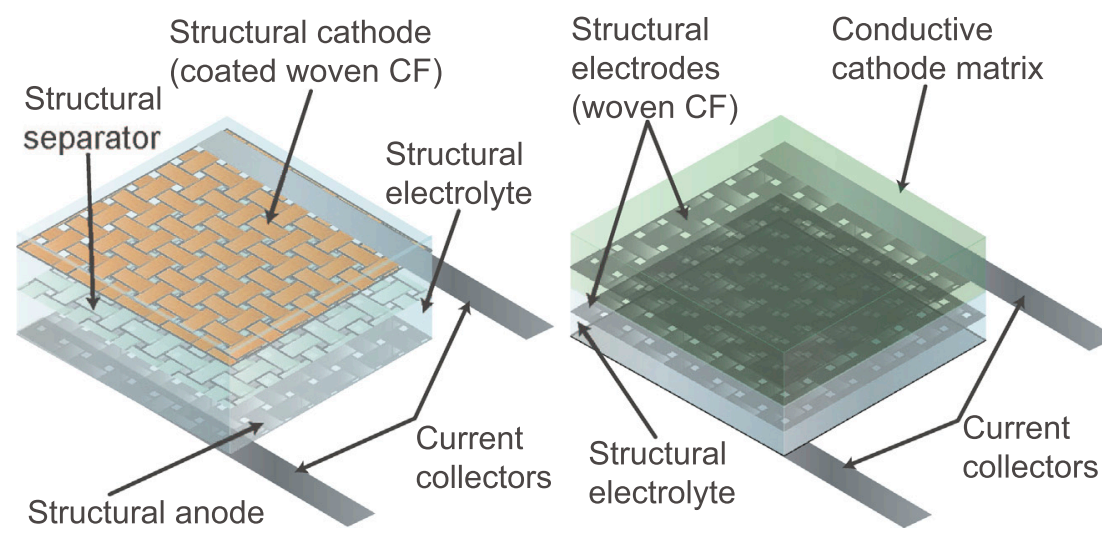

(woven CF)
B Structural EDLC fiber-level

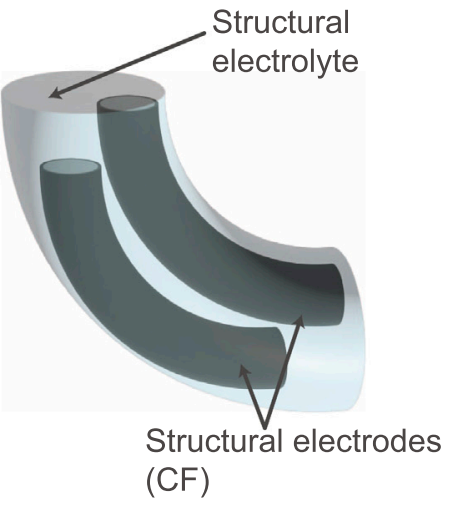

D Structural battery fiber-level

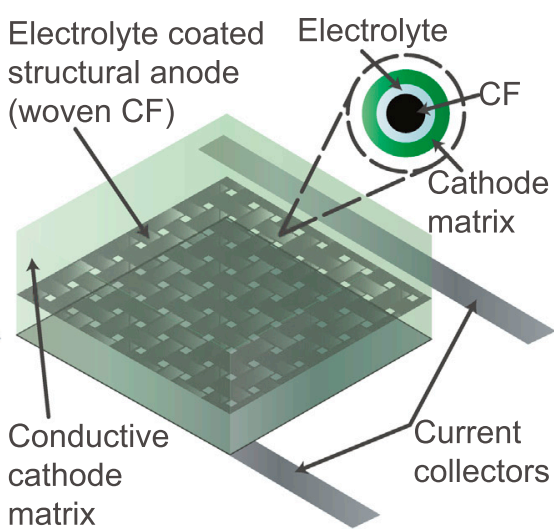

FIGURE 2 | Scheme of (A) structural EDLC laminates, (B) a structural EDLC fiber-level, (C) structural battery laminates, and (D) a structural battery fiber-level.

et al., 2016; Hudak et al., 2017; Flouda et al., 2019b; Javaid et al., 2021), metal particles (Mapleback et al., 2020), and metal oxides (Deka et al., 2016; Liu et al., 2016; Deka et al., 2017b; Choi et al., 2017; Deka et al., 2019; Sha et al., 2021).

LIBs exhibit relatively high energy density $\left(\sim 240 \mathrm{Wh} \mathrm{kg}^{-1}\right.$ and $640 \mathrm{Wh} \mathrm{L}^{-1}$ ), long cycle life, relatively high safety, and have a continuously decreasing cost (Armand et al., 2020). The general charge storage mechanism consists of Li ions being stored in, and released from a solid lattice, shuttling back and forth between the anode and cathode. Most of the SESD work in this area has focused on structural anodes, identifying polyacrylonitrile-based CFs with the optimal microstructure to promote good Li-ion intercalation (Wong et al., 2007; Ekstedt et al., 2010; Kjell et al., 2011; Jacques et al., 2012; Jacques et al., 2013; Kjell et al., 2013; Jacques et al., 2014; Hagberg et al., 2016; Feng et al., 2017; Yu et al., 2017; Fredi et al., 2018; Johannisson et al., 2018; Park et al., 2018; Xu et al., 2018; Moyer et al., 2020a; Thakur and Dong, 2020; Xu et al., 2020; Asp et al., 2021). The advantage is that the primary structural fibers act as the energy storage electrode, not simply a current collector; the volume changes may be small enough to be accommodated within the composite, with an appropriate structural electrolyte, and even open up opportunities for high performance actuation (Ferreira et al., 2016). To improve the energy density of the devices, surface modifications with $\mathrm{SnO}_{2}{ }^{81}$ and $\mathrm{MoS}_{2}$-containing anodes have been tried, exhibiting high capacities and excellent cycling stability due to the conversion processes occurring in the $\mathrm{SnO}_{2}$ and $\mathrm{MoS}_{2}$ anodes.

To date only a limited number of studies on structural cathodes have been published, generally packing the cathode powder into the matrix either around each fiber (Hagberg et al., 2018) or within a separate structural cathode ply (Figures 2C,D) (Galos et al., 2020). The fiber architecture minimizes ionic resistances but increases the risk of shorts; the laminate architecture simplifies fabrication and current collection. Examples of structural $\mathrm{LiB}$ cathodes $\left(\mathrm{LiCoO}_{2}\right)$ (Pereira et al., 2007; Liu et al., 2009; Roberts and Aglietti, 2010; Javaid and Ali, 2018), lithium iron phosphate $\left(\mathrm{LiFePO}_{4}\right)$ (Snyder et al., 2006; Ekstedt et al., 2010; Carlson, 2013; Hagberg et al., 2018; Bouton et al., 2019; Moyer et al., 2020b), and lithium nickel manganese cobalt oxide (NMC) (Ladpli et al., 2019). $\mathrm{LiCoO}_{2}$ electrodes are a popular choice for use with mobile devices such as smartphones, laptops, and digital cameras (Liu et al., 2015). However, using 
cobalt raises issues with geo-politics and scarcity, particularly with the projection of at least a tenfold production increase of EVs in the next decade (Li et al., 2020). $\mathrm{LiFePO}_{4}$ and NMC are two of the main cobalt-free and low-cobalt battery chemistries that are on the market. $\mathrm{LiFePO}_{4}$ batteries benefit from flat voltage profile, low material cost, and abundant material supply, making them ideal for electric transportation. However, they have lower voltage and lower energy density than $\mathrm{LiCoO}_{2}$ or NMC (Zhang, 2011). Moreover, they suffer from high electrical resistivity presenting a challenge to develop high cathodic mass fraction for mass efficiency in structural device configurations (Snyder et al., 2015). In NMC, nickel provides the cell with high-specific energy, thus the prevailing trend is to increase the nickel content. However, high-Ni cathode materials generally suffer from lattice and surface instabilities that diminish the longevity of the battery (Lee et al., 2021).

\section{FUTURE NEEDS AND PROSPECTS}

The choice of SESD type and chemistry must be related to the energy/power density required for the chosen application. Recent work has identified different targets with different balances of properties (Nguyen et al., 2021). Very often, in particular applications, the implementation of SESDs will be associated with other system savings, thus the required performance, and potential benefit, is very context dependent. More accessible gains can be accessed by developing secondary systems (e.g. aircraft cabin flooring) with more modest energy and power density demands. Here, the best outcomes may be achieved using alternative chemistries; for example, avoiding the fire risk and encapsulation challenges of LIBs, by using aqueous polymeric pseudocapacitors. More ambitious goals (e.g. full aircraft electrification) will require dramatic improvements in specific performance; SESDs may be one of the few approaches that can deliver the high effective energy densities required, because the structural functionality may allow much of the device mass to be discounted (Carlstedt and Asp, 2020).

The quest for high energy density structural EDLCs requires CFs to be modified to improve charge storage. Fiber etching to increase surface area typically reduces mechanical strength in fibers, although modest activation of fiber surfaces has been demonstrated without degradation (Shirshova et al., 2014; Snyder et al., 2015). The addition of carbon-based nanomaterials on the fiber or laminate surface can enhance electrochemical surface areas as well as interfacial properties (Anthony et al., 2018; Senokos et al., 2020). Adding nanostructured carbon throughout the multifunctional electrode matrix maximizes the utilization of the available volume (Qian et al., 2013b); however, it is important not to add excess material, as the effective structural fiber volume fraction is then reduced.

Most of the work on structural pseudocapacitors has coated the structural carbon with conductive polymers or metal oxides; usually resulting in a significant decrease in mechanical performance of the composites, although appropriate nanostructuring of the interface may resolve these issues.
Transition metal chalcogenides $\left(\mathrm{VS}_{2}, \mathrm{CuS}, \mathrm{CoE}_{2}, \mathrm{NiS}_{2}, \mathrm{NiSe}_{2}\right)$, rare-earth metal sulfides $\left(\mathrm{La}_{2} \mathrm{~S}_{3}\right.$ and $\left.\mathrm{Sm}_{2} \mathrm{~S}_{3}\right)$, and layer-structured chalcogenides ( $\mathrm{MoS}_{2}$ and $\mathrm{SnSe}$ ) have been previously proposed as attractive electrode materials for flexible devices due their ability to host redox reactions and the tunable gap between the layers that can intercalate ions from the electrolyte (Palchoudhury et al., 2019). MXenes, 2D transition metal carbides and nitrides, have also shown promising results in flexible supercapacitors (Zhao et al., 2015; Yan et al., 2017; Zhang et al., 2017; Couly et al., 2018; Zheng et al., 2019), in both aqueous and ionic liquid electrolytes. Both transition metal (di) chalcogenides and MXenes could be extended to SESDs. To minimize the effect of modulating the primary fiber-matrix interfaces, and maximize the active volume, these species can be incorporated within a multifunctional matrix material, throughout the structural electrode; electrical conductivity can be supplemented by carbon nanomaterials or a continuous carbon aerogel network (Qian et al., 2013b), if required. In this case, the primary CFs may simply act as structural current collector. The contribution of the structural matrix will be limited by the available matrix volume fraction. Increasing the matrix volume fraction will not generally be attractive as the primary structural fiber volume fraction will fall, significantly degrading structural performance.

Most of the studies on structural LIBs used CFs as anodes, but many aspects, including dendrite formation and crack nucleation during the lithiation/delithiation cycles, have yet to be deeply addressed (Danzi et al., 2021). Interfacial adhesion between CFs and the structural electrolyte will be vital for the mechanical and electrochemical properties of SESDs; thus operando and modelling studies are needed to analyze the inherent behaviors, particularly over multiple cycles. The problem is even more complex where additional coatings of high-capacity materials are applied, although nanoscale texture can assist load transfer (Qian et al., 2008; Qian et al., 2010; Mikhalchan and Vilatela, 2019). The electrochemical performance of existing CFs has been enhanced by, for example, decorating them with different metal oxides (e.g. $\left.\mathrm{NiO}, \mathrm{SnO}_{2}, \mathrm{ZnO}, \mathrm{ZnCo}_{2} \mathrm{O}_{4}\right)(\mathrm{Han}$ et al., 2019; Han et al., 2020a; Han et al., 2020b; Han et al., 2020c). All these composites exhibited enhanced Li storage performance. However, no mechanical studies were performed; since the electrochemical testing was performed with a conventional, rather than multifunctional electrolyte, their suitability for SESDs is not yet clear. Computational studies have proposed $\mathrm{Co}_{3} \mathrm{O}_{4}$ as structural anode (Hu et al., 2021); experimental testing is yet to be performed. Most of high-capacity anode materials, including $\mathrm{Co}_{3} \mathrm{O}_{4}$ and silicon, exhibit low cycling stability, due to volume expansion during $\mathrm{Li}$ insertion/extraction. In general, the main challenge for these high energy density insertion anodes, whether designed at either fiber or laminate level, may remain how to accommodate volume changes during cycling within a structural composite material.

Due to its high theoretical capacity $\left(3860 \mathrm{mAh} \mathrm{g}^{-1}\right)$, low density $\left(0.59 \mathrm{~g} \mathrm{~cm}^{-3}\right)$ and negative electrochemical potential $(-3.04 \mathrm{~V}$ vs. SHE), Li metal has many attractions as anode for batteries. However, Li-metal presents particular challenges with safety, due to potential dendrite formation and associated fire risk. In any case, in a SESD context, the pure metal will make little 
mechanical contribution, both due to its intrinsic properties, and its structure as it dissolves and redeposits. Reactive anodes exploiting silicon, tin, or phosphorus, similarly may have limited value as the large volume changes may be hard to accommodate, and cycle life tends to be low. However, these additional components could be incorporated within a multifunctional matrix approach. Thermal runaway in case of damage by mechanical loads is a concern in all SESD but maybe be mitigated by the intrinsically distributed energy storage, large surface area for cooling, and opportunities for self-limiting delamination (Kalnaus et al., 2021). Nevertheless, where high volumetric and gravimetric energy densities are needed, primary aluminum-air and secondary zinc-air may offer better damage tolerance than Li systems (Hopkins et al., 2020). 3D printing has been proposed as an appropriate fabrication method for structural metal-oxygen batteries as the micro-structures and shapes of electrodes/electrolytes/current collectors/packaging materials can be controlled, improving mechanical and electrochemical performance (Zeng et al., 2020). However, the autophageous nature of pure metal batteries may limit their relevance as SESDs.

Conversion-type cathodes, such as sulfur, and oxygen, typically store 2-3 Li-ions per anion and therefore could potentially exhibit higher theoretical energy densities compared to the current LIBs (e.g. $\mathrm{Li}-\mathrm{O}_{2}, 3505 \mathrm{Wh} \mathrm{kg}^{-1}$; $\mathrm{Li}-\mathrm{S}$, $2600 \mathrm{Wh} \mathrm{kg}^{-1}$ ) (Guo et al., 2017). Even so, they suffer from low conductivity (leading to low capacity utilization, poor kinetics, and poor reversibility of conversion reactions) and voltage hysteresis (typically linked to poor electronic resistance of the materials leading to low energy efficiency) (Wu and Yushin, 2017). Traditionally, conductive carbons, conducting polymers, metal organic frameworks and various metal oxides have been used to improve the conductivities of some conversion cathodes and reduce their dissolution during cycling (Guo and Fu, 2018). Conversion-type cathodes may be attractive in SESDs as CFs and CF-supported aerogels (Qian et al., 2013b; Nguyen et al., 2019) could potentially solve the low conductivity and voltage hysteresis issues. To date, there has only been one approach towards structural Li-S batteries (Huang et al., 2020); yet its electrolyteto-sulfur weight ratio $(\sim 27)$ was extremely high for practical applications given that an excess of electrolyte (ratio $>4$ ) has an adverse impact on the energy density of the battery at the system level. Moreover, the energy density reported is calculated based on the sulfur contained in the electrode, ignoring the sulfur in the catholyte, thus, overestimating the energy density of the device in a practical sense.

Concerns about Li resource shortages have led to an interest in alternative chemistries in battery applications. CFs have been tested as anodes in potassium-ion (Harnden et al., 2021) and sodium-ion batteries (Harnden et al., 2018). Potassium-insertion gives a larger voltage-strain coupling than $\mathrm{Na}$ probably due to a slightly higher ionic diffusion coefficient; therefore, potassiuminsertion appears more promising for creating actuation multifunctionality. Still, Li-insertion appears most promising for high-performance SESDs, where mass is the underlying driver.
As a more radical alternative to LIB or other high voltage systems, aqueous zinc batteries may be attractive due to the low cost of $\mathrm{Zn}$, its low toxicity, low flammability, high stability and compatibility in aqueous electrolytes, as well as a high theoretical anode gravimetric and volumetric capacity $\left(820 \mathrm{mAh}^{-1}\right.$, $5851 \mathrm{mAh} \mathrm{cm}^{-3}$ ) (Jia et al., 2020). A CF $\mathrm{Zn}-\mathrm{MnO}_{2}$ structural composite battery was tested using a gel electrolyte exhibiting reasonably high stiffness and electrochemical performance (Chen et al., 2021). As the energy density was calculated per active material, instead of per device, it is difficult to assess the weight saving benefits of the SESDs, but an embodiment with a multifunctional matrix electrode could prove beneficial. The use of an aqueous electrolyte has obvious attractions for SESDs, reducing fire risk, toxicity, and minimizing encapsulation challenges.

The fabrication of batteries with inorganic cathodes is costly and environmentally damaging, from the extraction of the transition metals in ores with low metal content (Mauger et al., 2019), to the preparation of the active materials. Organic electroactive components can be used in both pseudocapacitors and organic batteries (small molecule or polymer) (Muench et al., 2016; Chen et al., 2020; John et al., 2020) and may offer environmental benefits both in production and recycling. In principle, these organic electrodes are composed of naturally abundant elements and they are less environmentally challenging compared to metal-based batteries. Both n- and p-type storage mechanisms can be implemented in organic electrodes, enabling various cell or electrode configurations (Poizot et al., 2018). The production of CFs themselves is relatively energy intensive; whilst over their lifetime, they may make a positive contribution to reducing emissions, though improved fuel efficiency in application, there is significant interest in developing "greener" CFs from renewable resources. Whilst absolute mechanical performance is relatively low, it is approaching the range needed for automotive applications and there may be opportunities for new types of multifunctional CFs (Mariano et al., 2014; Baker and Rials, 2013).

\section{CONCLUDING REMARKS}

Structural energy storage devices are a promising approach to reduce the weight of the battery pack, and hence increase range, in electric transportation. Many advances have been made in CF for structural EDLCs and LIB anodes, although the development of effective structural electrolytes remains challenging. The fibermatrix interface also needs to be optimized to ensure both load transfer and electrochemical access, as well as accommodating intercalation-induced strains in structural batteries. Electrochemical performance can be enhanced by adding additional electroactive components, either coated at the fiber/ lamina surface, or more beneficially incorporated throughout the multifunctional electrode matrix volume. There is significant scope to develop this concept, which is likely to be essential to developing structural cathodes to complement existing structural anodes. 
Whilst high energy densities are a key driver, other factors may be more crucial; in some applications, more modest performance can offer significant benefits when the whole system is considered. In SESDs, longevity is particularly important, as the energy storage function is an inherent part of the whole product and cannot easily be replaced. In addition, the distribution of the electrochemical system over a large area, where fastenings and other connections are required, makes encapsulation and air-free fabrication challenging. SESDs may therefore particularly benefit from high cyclability systems, and aqueous, or at least water-tolerant, chemistries. Fire, smoke, and toxicity concerns will vary with application. The distributed character of the energy storage in SESDs tends to mitigate fire risk, and initial trials have indicated benign failures (Kalnaus et al., 2021); however, chemistries may be selected to further reduce risk. In addition, materials researchers are increasingly considering the sustainability and full life cycle analysis of new systems; there is significant scope to implement bio-derived materials, for both carbonaceous and organic redoxactive constituents.

Fair performance comparisons in multifunctional applications can be difficult, but a variety of methodologies are emerging (Carlstedt and Asp, 2020; Johannisson et al., 2020; Nguyen et al., 2021). As well as the intrinsic electrochemical performance of different chemistries, it is important to consider device energy densities in existing embodiments and projected to future

\section{REFERENCES}

Acauan, L. H., Zhou, Y., Kalfon-Cohen, E., Fritz, N. K., and Wardle, B. L. (2019). Multifunctional Nanocomposite Structural Separators for Energy Storage. Nanoscale 11, 21964-21973. doi:10.1039/c9nr06954b

Aderyani, S., Flouda, P., Lutkenhaus, J. L., and Ardebili, H. (2019). The Effect of Nanoscale Architecture on Ionic Diffusion in rGo/aramid Nanofiber Structural Electrodes. J. Appl. Phys. 125 (18), 185106. doi:10.1063/1.5087280

Anthony, D. B., Sui, X., Kellersztein, I., De Luca, H. G., White, E. R., Wagner, H. D., et al. (2018). Continuous Carbon Nanotube Synthesis on Charged Carbon Fibers. Composites A: Appl. Sci. Manufacturing 112, 525-538. doi:10.1016/ j.compositesa.2018.05.027

Armand, M., Axmann, P., Bresser, D., Copley, M., Edström, K., Ekberg, C., et al. (2020). Lithium-ion Batteries - Current State of the Art and Anticipated Developments. J. Power Sourc. 479, 228708. doi:10.1016/j.jpowsour.2020.228708

Asp, L. E., Bouton, K., Carlstedt, D., Duan, S., Harnden, R., Johannisson, W., et al. (2021). A Structural Battery and its Multifunctional Performance. Adv. Energ. Sustain. Res. 2 (3), 2000093. doi:10.1002/aesr.202000093

Asp, L. E., and Greenhalgh, E. S. (2014). Structural Power Composites. Composites Sci. Tech. 101, 41-61. doi:10.1016/j.compscitech.2014.06.020

Asp, L. E., Johansson, M., Lindbergh, G., Xu, J., and Zenkert, D. (2019). Structural Battery Composites: A Review. Funct. Compos. Struct. 1, 042001, 2019. Available at: https://iopscience.iop.org/article/10.1088/2631-6331/ab5571. doi:10.1088/2631-6331/ab5571

Asp, L. E., Leijonmarck, S., Carlson, T., and Lindbergh, G. (2015). Realisation of Structural Battery Composite Materials in 20th International Conference on Composite Materials, ICCM20, Copenhagen, Denmark. doi:10.13140/RG.2.1.2029.1922

Baker, D. A., and Rials, T. G. (2013). Recent Advances in Low-Cost Carbon Fiber Manufacture from Lignin. J. Appl. Polym. Sci. 130, 713-728. doi:10.1002/ app.39273

Benson, J., Kovalenko, I., Boukhalfa, S., Lashmore, D., Sanghadasa, M., and Yushin, G. (2013). Multifunctional CNT-Polymer Composites for Ultra-Tough Structural Supercapacitors and Desalination Devices. Adv. Mater. 25, 6625-6632. doi:10.1002/adma.201301317 embodiments that might be compatible with the given storage system. Consideration must be given to the optimal architecture (fiber or laminate level), the need for current collection, and encapsulation, as well as the implications for mechanical integrity and load-carrying capacity. New modelling approaches are needed that combine the relevant thermomechanicalelectrochemical processes. SESD composites represent an important and stimulating field of research, that requires interdisciplinary collaborations to accelerate progress towards real world deployment.

\section{AUTHOR CONTRIBUTIONS}

AN-S: Conceptualization, Writing-Original Draft, Funding acquisition. MS: Writing-Review and Editing, Funding acquisition. Both authors contributed to the article and approved the submitted version.

\section{FUNDING}

This project has received funding from the European Union's Horizon 2020 research and innovation programme under the Marie Sklodowska-Curie grant agreement No 838892.

Bouton, K., Chen, B., Zenkert, D., and Lindbergh, G. (2019). Structural Positive Electrodes for Multifunctional Composite Materials. ICCM Int. Conf. Compos. Mater.

Carlstedt, D., and Asp, L. E. (2020). Performance Analysis Framework for Structural Battery Composites in Electric Vehicles. Composites B: Eng. 186, 107822. doi:10.1016/j.compositesb.2020.107822

Chen, J., Zhou, Y., Islam, M. S., Cheng, X., Brown, S. A., Han, Z., et al. (2021). Carbon Fiber Reinforced Zn-MnO2 Structural Composite Batteries. Composites Sci. Tech. 209, 108787. doi:10.1016/j.compscitech.2021.108787

Chen, R., Bresser, D., Saraf, M., Gerlach, P., Balducci, A., Kunz, S., et al. (2020). A Comparative Review of Electrolytes for Organic-Material-Based EnergyStorage Devices Employing Solid Electrodes and Redox Fluids. ChemSusChem 13 (9), 2205-2219. doi:10.1002/cssc.201903382

Chen, Y., Amiri, A., Boyd, J. G., and Naraghi, M. (2019). Promising Trade-Offs Between Energy Storage and Load Bearing in Carbon Nanofibers as Structural Energy Storage Devices. Adv. Funct. Mater. 29(3), 1901425, 2019. Available at: https://onlinelibrary.wiley.com/doi/abs/10.1002/adfm.201901425. doi:10.1002/ adfm. 201901425

Chen, Y., Cai, J., Boyd, J. G., Kennedy, W. J., and Naraghi, M. (2018). Mechanics of Emulsion Electrospun Porous Carbon Fibers as Building Blocks of Multifunctional Materials. ACS Appl. Mater. Inter. 10, 38310-38318. doi:10.1021/acsami.8b10499

Choi, C., Kim, J. H., Sim, H. J., Di, J., Baughman, R. H., and Kim, S. J. (2017). Supercapacitors: Microscopically Buckled and Macroscopically Coiled Fibers for Ultra-Stretchable Supercapacitors. Adv. Energ. Mater. 7 (6), 1602021. doi:10.1002/aenm.201770029

Couly, C., Alhabeb, M., Van Aken, K. L., Kurra, N., Gomes, L., Navarro-Suárez, A. M., et al. (2018). Asymmetric Flexible MXene-Reduced Graphene Oxide MicroSupercapacitor. Adv. Electron. Mater. 4, 1700339. doi:10.1002/aelm.201700339

Danzi, F., Salgado, R. M., Oliveira, J. E., Arteiro, A., Camanho, P. P., and Braga, M. H. (2021). Structural Batteries: A Review. Molecules. Molecules 26, 2203. doi:10.3390/molecules26082203

Deka, B. K., Hazarika, A., Kim, J., Kim, N., Jeong, H. E., Park, Y.-B., et al. (2019). Bimetallic Copper Cobalt Selenide Nanowire-Anchored Woven Carbon FiberBased Structural Supercapacitors. Chem. Eng. J. 355, 551-559. doi:10.1016/ j.cej.2018.08.172 
Deka, B. K., Hazarika, A., Kim, J., Park, Y.-B., and Park, H. W. (2016). Multifunctional $\mathrm{CuO}$ Nanowire Embodied Structural Supercapacitor Based on Woven Carbon Fiber/ionic Liquid-Polyester Resin. Composites Part A: Appl. Sci. Manufacturing 87, 256-262. doi:10.1016/j.compositesa.2016.05.007

Deka, B. K., Hazarika, A., Kim, J., Park, Y.-B., and Park, H. W. (2017). Recent Development and Challenges of Multifunctional Structural Supercapacitors for Automotive Industries. Int. J. Energ. Res. 41, 1397-1411. Available at: http://doi. wiley.com/10.1002/er.3707. doi:10.1002/er.3707

Deka, B. K., Hazarika, A., Kwon, O., Kim, D., Park, Y.-B., and Park, H. W. (2017). Multifunctional Enhancement of Woven Carbon fiber/ZnO Nanotube-Based Structural Supercapacitor and Polyester ResinDomain Solid-Polymer Electrolytes. Chem. Eng. J. 325, 672-680. doi:10.1016/j.cej.2017.05.093

Ekstedt, S., Wysocki, M., and Asp, L. E. (2010). Structural Batteries Made from Fibre Reinforced Composites. Plastics, Rubber and Composites 39, 148-150. doi:10.1179/174328910x12647080902259

Feng, M., Wang, S., Yu, Y., Feng, Q., Yang, J., and Zhang, B. (2017). Carboxyl Functionalized Carbon Fibers with Preserved Tensile Strength and Electrochemical Performance Used as Anodes of Structural Lithium-Ion Batteries. Appl. Surf. Sci. 392, 27-35. doi:10.1016/j.apsusc.2016.09.017

Ferreira, A. D. B. L., Nóvoa, P. R. O., and Marques, A. T. (2016). Multifunctional Material Systems: A State-Of-The-Art Review. Compos. Structures 151, 3-35. doi:10.1016/j.compstruct.2016.01.028

Flouda, P., Feng, X., Boyd, J. G., Thomas, E. L., Lagoudas, D. C., and Lutkenhaus, J. L. (2019). Interfacial Engineering of Reduced Graphene Oxide for Aramid Nanofiber-Enabled Structural Supercapacitors. Batteries \& Supercaps 2, 464-472. doi:10.1002/batt.201800137

Flouda, P., Shah, S. A., Lagoudas, D. C., Green, M. J., and Lutkenhaus, J. L. (2019). Highly Multifunctional Dopamine-Functionalized Reduced Graphene Oxide Supercapacitors. Matter 1, 1532-1546. doi:10.1016/j.matt.2019.09.017

Fredi, G., Jeschke, S., Boulaoued, A., Wallenstein, J., Rashidi, M., Liu, F., et al. (2018). Graphitic Microstructure and Performance of Carbon Fibre Li-Ion Structural Battery Electrodes. Multifunct. Mater. 1, 015003. doi:10.1088/2399$7532 / \mathrm{aab} 707$

Galos, J., Best, A. S., and Mouritz, A. P. (2020). Multifunctional sandwich Composites Containing Embedded Lithium-Ion Polymer Batteries under Bending Loads. Mater. Des. 185, 108228. doi:10.1016/j.matdes.2019.108228

Galos, J., Pattarakunnan, K., Best, A. S., Kyratzis, I. L., Wang, C. H., and Mouritz, A. P. (2021). Energy Storage Structural Composites with Integrated Lithium-Ion Batteries: A Review. Adv. Mater. Technol. 6(8), 2001059. doi:10.1002/ admt.202001059

Ganguly, A., Karakassides, A., Benson, J., Hussain, S., and Papakonstantinou, P. (2020). Multifunctional Structural Supercapacitor Based on Urea-Activated Graphene Nanoflakes Directly Grown on Carbon Fiber Electrodes. ACS Appl. Energ. Mater. 3, 4245-4254. Available at: https://pubs.acs.org/doi/10.1021/ acsaem.9b02469. doi:10.1021/acsaem.9b02469

Greenhalgh, E., Ankersen, J., Asp, L., Bismarck, A., Fontana, Q., Houlle, M., et al. (2015). Mechanical, Electrical and Microstructural Characterisation of Multifunctional Structural Power Composites. J. Compos. Mater. 49, 1823-1834. doi:10.1177/0021998314554125

Guo, W., and Fu, Y. (2018). A Perspective on Energy Densities of Rechargeable Li-S Batteries and Alternative Sulfur-Based Cathode Materials. Energy Environ. Mater. 1, 20-27. doi:10.1002/eem2.12003

Guo, Y., Li, H., and Zhai, T. (2017). Reviving Lithium-Metal Anodes for NextGeneration High-Energy Batteries. Adv. Mater. 29, 1-25. doi:10.1002/ adma.201700007

Hagberg, J., Leijonmarck, S., and Lindbergh, G. (2016). High Precision Coulometry of Commercial PAN-Based Carbon Fibers as Electrodes in Structural Batteries. J. Electrochem. Soc. 163, A1790-A1797. doi:10.1149/2.0041609jes

Hagberg, J., Maples, H. A., Alvim, K. S. P., Xu, J., Johannisson, W., Bismarck, A., et al. (2018). Lithium Iron Phosphate Coated Carbon Fiber Electrodes for Structural Lithium Ion Batteries. Composites Sci. Tech. 162, 235-243. doi:10.1016/j.compscitech.2018.04.041

Han, Q., Li, X., Wang, F., Han, Z., Geng, D., Zhang, W., et al. (2019). Carbon Fiber@Pore-ZnO Composite as Anode Materials for Structural Lithium-Ion Batteries. J. Electroanalytical Chem. 833, 39-46. doi:10.1016/ j.jelechem.2018.11.014
Han, Q., Shi, M., Han, Z., Zhang, W., Li, Y., Zhang, X., et al. (2020). Synthesis of One-Dimensional PAN-Based Carbon Fiber/NiO Composite as an Anode Material for Structural Lithium-Ion Batteries. Ionics 26 (12), 1-6. doi:10.1007/s11581-020-03762-8

Han, Q., Zhang, X., Zhang, W., Li, Y., and Sheng, Y. (2020). Preparation of Multifunctional P-CF@SnO2-MOF Composite Used as Structural Anode Materials. J. Electroanalytical Chem. 871, 114355 . doi:10.1016/ j.jelechem.2020.114355

Han, Q., Zhang, X., Zhang, W., Li, Y., and Zhang, Z. (2020). Preparation of Multifunctional Structural P-CF@ZnCo2O4 Composites Used as Structural Anode Materials. J. Alloys Comp. 842, 155743. doi:10.1016/ j.jallcom.2020.155743

Harnden, R., Peuvot, K., Zenkert, D., and Lindbergh, G. (2018). Multifunctional Performance of Sodiated Carbon Fibers. J. Electrochem. Soc. 165, B616-B622. doi:10.1149/2.0971813jes

Harnden, R., Zenkert, D., and Lindbergh, G. (2021). Potassium-insertion in Polyacrylonitrile-Based Carbon Fibres for Multifunctional Energy Storage, Morphing, and Strain-Sensing. Carbon 171, 671-680. doi:10.1016/ j.carbon.2020.09.042

Hopkins, B. J., Long, J. W., Rolison, D. R., and Parker, J. F. (2020). HighPerformance Structural Batteries. Joule 4, 2240-2243. doi:10.1016/ j.joule.2020.07.027

Hu, Z., Fu, Y., Hong, Z., Huang, Y., Guo, W., Yang, R., et al. (2021). Composite Structural Batteries With Co3O4/CNT Modified Carbon Fibers As Anode: Computational Insights On The Interfacial Behavior. Compos. Sci. Technol. 201, 108495. doi:10.1016/j.compscitech.2020.108495

Huang, W., Wang, P., Liao, X., Chen, Y., Borovilas, J., Jin, T., et al. (2020). Mechanically-Robust Structural Lithium-Sulfur Battery with High Energy Density. Energ. Storage Mater. 33, 416-422. doi:10.1016/j.ensm.2020.08.018

Hudak, N. S., Schlichting, A. D., and Eisenbeiser, K. (2017). Structural Supercapacitors with Enhanced Performance Using Carbon Nanotubes and Polyaniline. J. Electrochem. Soc. 164, A691-A700. doi:10.1149/2.0721704jes

Ihrner, N., Johannisson, W., Sieland, F., Zenkert, D., and Johansson, M. (2017). Structural Lithium Ion Battery Electrolytes via reaction Induced PhaseSeparation. J. Mater. Chem. A. 5, 25652-25659. doi:10.1039/c7ta04684g

Jacques, E., Hellqvist Kjell, M., Zenkert, D., Lindbergh, G., and Behm, M. (2013). Expansion of Carbon Fibres Induced by Lithium Intercalation for Structural Electrode Applications. Carbon 59, 246-254. doi:10.1016/j.carbon.2013.03.015

Jacques, E., H. Kjell, M., Zenkert, D., and Lindbergh, G. (2014). The Effect of Lithium-Intercalation on the Mechanical Properties of Carbon Fibres. Carbon 68, 725-733. doi:10.1016/j.carbon.2013.11.056

Jacques, E., Kjell, M. H., Zenkert, D., Lindbergh, G., Behm, M., and Willgert, M. (2012). Impact of Electrochemical Cycling on the Tensile Properties of Carbon Fibres for Structural Lithium-Ion Composite Batteries. Composites Sci. Tech. 72, 792-798. doi:10.1016/j.compscitech.2012.02.006

Javaid, A., and Ali, M. Z. (2018). Multifunctional Structural Lithium Ion Batteries for Electrical Energy Storage Applications. Mater. Res. Express 5, 055701, 2018 Available at: https://iopscience.iop.org/article/10.1088/2053-1591/aabeb1. doi:10.1088/2053-1591/aabeb1

Javaid, A., Ho, K., Bismarck, A., Shaffer, M., Steinke, J., and Greenhalgh, E. (2014). Multifunctional Structural Supercapacitors for Electrical Energy Storage Applications. J. Compos. Mater. 48, 1409-1416. doi:10.1177/ 0021998313487239

Javaid, A., Ho, K., Bismarck, A., Steinke, J., Shaffer, M., and Greenhalgh, E. (2016). Carbon Fibre-Reinforced Poly(ethylene Glycol) Diglycidylether Based Multifunctional Structural Supercapacitor Composites for Electrical Energy Storage Applications. J. Compos. Mater. 50, 2155-2163. doi:10.1177/ 0021998315602324

Javaid, A., Ho, K., Bismarck, A., Steinke, J., Shaffer, M., and Greenhalgh, E. (2018). Improving the Multifunctional Behaviour of Structural Supercapacitors by Incorporating Chemically Activated Carbon Fibres and Mesoporous Silica Particles as Reinforcement. J. Compos. Mater. 52, 3085-3097. doi:10.1177/ 0021998318761216

Javaid, A., and Irfan, M. (2018). Multifunctional Structural Supercapacitors Based on Graphene Nanoplatelets/carbon Aerogel Composite Coated Carbon Fiber Electrodes. Mater. Res. Express 6, 016310, 2018 . Available at: https://iopscience. iop.org/article/10.1088/2053-1591/aae862. doi:10.1088/2053-1591/aae862 
Javaid, A., Khalid, O., Shakeel, A., and Noreen, S. (2021). Multifunctional Structural Supercapacitors Based on Polyaniline Deposited Carbon Fiber Reinforced Epoxy Composites. J. Energ. Storage 33, 102168. doi:10.1016/ j.est. 2020.102168

Jia, X., Liu, C., Neale, Z. G., Yang, J., and Cao, G. (2020). Active Materials for Aqueous Zinc Ion Batteries: Synthesis, Crystal Structure, Morphology, and Electrochemistry. Chem. Rev. 120 (15), 7795-7866. Available at: https://pubs. acs.org/doi/10.1021/acs.chemrev.9b00628. doi:10.1021/acs.chemrev.9b00628

Johannisson, W., Ihrner, N., Zenkert, D., Johansson, M., Carlstedt, D., Asp, L. E., et al. (2018). Multifunctional Performance of a Carbon Fiber UD Lamina Electrode for Structural Batteries. Composites Sci. Tech. 168, 81-87. doi:10.1016/j.compscitech.2018.08.044

Johannisson, W., Nguyen, S., Lindbergh, G., Zenkert, D., Greenhalgh, E., Shaffer, M., et al. (2020). A Residual Performance Methodology to Evaluate Multifunctional Systems. Multifunct. Mater. 3, 12, 2020 . Available at: https://iopscience.iop.org/article/10.1088/2399-7532/ab8e95. doi:10.1088/ 2399-7532/ab8e95

John, G., Miroshnikov, M., Mahankali, K., Thangavel, N. K., Satapathy, S., Arava, L. M. R., et al. (2020). Bioderived Molecular Electrodes for Next-Generation Energy-Storage Materials. ChemSusChem 13 (9), 2186-2204. doi:10.1002/ cssc.201903589

Kalnaus, S., Asp, L. E., Li, J., Veith, G. M., Nanda, J., Daniel, C., et al. (2021). Multifunctional Approaches for Safe Structural Batteries. J. Energ. Storage 40, 102747. doi:10.1016/j.est.2021.102747

Kjell, M. H., Jacques, E., Zenkert, D., Behm, M., and Lindbergh, G. (2011). PANBased Carbon Fiber Negative Electrodes for Structural Lithium-Ion Batteries. J. Electrochem. Soc. 158, A1455. doi:10.1149/2.053112jes

Kjell, M. H., Zavalis, T. G., Behm, M., and Lindbergh, G. (2013). Electrochemical Characterization of Lithium Intercalation Processes of PAN-Based Carbon Fibers in a Microelectrode System. J. Electrochem. Soc. 160, A1473-A1481. doi:10.1149/2.054309jes

Kwon, S. R., Harris, J., Zhou, T., Loufakis, D., Boyd, J. G., and Lutkenhaus, J. L. (2017). Mechanically Strong Graphene/Aramid Nanofiber Composite Electrodes for Structural Energy and Power. ACS Nano 11, 6682-6690. doi:10.1021/acsnano.7b00790

Ladpli, P., Nardari, R., Kopsaftopoulos, F., and Chang, F.-K. (2019). Multifunctional Energy Storage Composite Structures with Embedded Lithium-Ion Batteries. J. Power Sourc. 414, 517-529. doi:10.1016/j.jpowsour.2018.12.051

Lee, S., Li, W., Dolocan, A., Celio, H., Park, H., Warner, J. H., et al. (2021). In-Depth Analysis of the Degradation Mechanisms of High-Nickel, Low/No-Cobalt Layered Oxide Cathodes for Lithium-Ion Batteries. Adv. Energ. Mater. 11, 2100858. doi:10.1002/aenm.202100858

Li, H., Wang, S., Feng, M., Yang, J., and Zhang, B. (2018). Self-assembly and Performances of Wrinkled rGO@carbon Fiber with Embedded SnO2 Nanoparticles as Anode Materials for Structural Lithium-Ion Battery. J. Mater. Sci. 53, 11607-11619. doi:10.1007/s10853-018-2401-6

Li, Q., Zhu, Y. Q., and Eichhorn, S. J. (2018). Structural Supercapacitors Using a Solid Resin Electrolyte with Carbonized Electrospun Cellulose/carbon Nanotube Electrodes. J. Mater. Sci. 53, 14598-14607. doi:10.1007/s10853018-2665-x

Li, W., Lee, S., and Manthiram, A. (2020). High-Nickel NMA: A Cobalt-Free Alternative to NMC and NCA Cathodes for Lithium-Ion Batteries. Adv. Mater. 32, 1-6. doi:10.1002/adma.202002718

Li, X., Rong, J., and Wei, B. (2010). Electrochemical Behavior of Single-Walled Carbon Nanotube Supercapacitors under Compressive Stress. ACS Nano 4, 6039-6049. doi:10.1021/nn101595y

Liu, P., Sherman, E., and Jacobsen, A. (2009). Design and Fabrication of Multifunctional Structural Batteries. J. Power Sourc. 189, 646-650. doi:10.1016/j.jpowsour.2008.09.082

Liu, W., Oh, P., Liu, X., Lee, M.-J., Cho, W., Chae, S., et al. (2015). NickelRich Layered Lithium Transition-Metal Oxide for High-Energy LithiumIon Batteries. Angew. Chem. Int. Ed. 54, 4440-4457. doi:10.1002/ anie. 201409262

Liu, X., Jervis, R., Maher, R. C., Villar-Garcia, I. J., Naylor-Marlow, M., Shearing, P. R., et al. (2016). 3D Printing: 3D-Printed Structural Pseudocapacitors (Adv. Mater. Technol. 9/2016). Adv. Mater. Technol. 1, 1-7. doi:10.1002/ admt.201670043
Mapleback, B. J., Simons, T. J., Shekibi, Y., Ghorbani, K., and Rider, A. N. (2020). Structural Composite Supercapacitor Using Carbon Nanotube Mat Electrodes with Interspersed Metallic Iron Nanoparticles. Electrochimica Acta 331, 135233. doi:10.1016/j.electacta.2019.135233

Mariano, M., Kissi, N. E., and Dufresne, A. (2014). Cellulose Nanocrystals and Related Nanocomposites: Review of some Properties and Challenges. J. Polym. Sci. B Polym. Phys. 52 (12). doi:10.1002/polb.23490

Mauger, A., Julien, C., Paolella, A., Armand, M., and Zaghib, K. (2019). Building Better Batteries in the Solid State: A Review.Materials. Materials (Basel) 12, 1-57. doi:10.3390/ma12233892

Mikhalchan, A., and Vilatela, J. J. (2019). A Perspective on High-Performance CNT Fibres for Structural Composites. Carbon 150, 191-215. Available at: https:// linkinghub.elsevier.com/retrieve/pii/S0008622319304567. doi:10.1016/ j.carbon.2019.04.113

Moyer, K., Boucherbil, N. A., Zohair, M., Eaves-Rathert, J., and Pint, C. L. (2020). Polymer Reinforced Carbon Fiber Interfaces for High Energy Density Structural Lithium-Ion Batteries. Sust. Energ. Fuels 4, 2661-2668. Available at: http://xlink.rsc.org/?DOI=D0SE00263A. doi:10.1039/d0se00263a

Moyer, K., Meng, C., Marshall, B., Assal, O., Eaves, J., Perez, D., et al. (2020). Carbon Fiber Reinforced Structural Lithium-Ion Battery Composite: Multifunctional Power Integration for CubeSats. Energ. Storage Mater. 24, 676-681. doi:10.1016/j.ensm.2019.08.003

Muench, S., Wild, A., Friebe, C., Häupler, B., Janoschka, T., and Schubert, U. S. (2016). Polymer-Based Organic Batteries. Chem. Rev. 116, 9438-9484. Available at: http://pubs.acs.org/doi/abs/10.1021/acs.chemrev.6b00070. doi:10.1021/acs.chemrev.6b00070

Muralidharan, N., Teblum, E., Westover, A. S., Schauben, D., Itzhak, A., Muallem, M., et al. (2018). Carbon Nanotube Reinforced Structural Composite Supercapacitor. Sci. Rep. 8, 1-9. doi:10.1038/s41598-018-34963-x

Nguyen, S., Anthony, D. B., Qian, H., Yue, C., Singh, A., Bismarck, A., et al. (2019). Mechanical and Physical Performance of Carbon Aerogel Reinforced Carbon Fibre Hierarchical Composites. Composites Sci. Tech. 182, 107720. doi:10.1016/ j.compscitech.2019.107720

Nguyen, S. N., Millereux, A., Pouyat, A., Greenhalgh, E. S., Shaffer, M. S. P., Kucernak, A. R. J., et al. (2021). Conceptual Multifunctional Design, Feasibility and Requirements for Structural Power in Aircraft Cabins. J. Aircraft 58, 677-687. doi:10.2514/1.c036205

Palchoudhury, S., Ramasamy, K., Gupta, R. K., and Gupta, A. (2019). Flexible Supercapacitors: A Materials Perspective. Front. Mater. 5, 1-9. doi:10.3389/ fmats.2018.00083

Park, M. Y., Kim, J.-H., Kim, D. K., and Kim, C. G. (2018). Perspective on Carbon Fiber Woven Fabric Electrodes for Structural Batteries. Fibers Polym. 19, 599-606. doi:10.1007/s12221-018-7937-1

Patel, A., Johnson, L., Arroyave, R., and Lutkenhaus, J. (2019). Design of Multifunctional Supercapacitor Electrodes Using an Informatics Approach. Mol. Syst. Des. Eng. 4 (3), 654-663. Available at: http://pubs.rsc.org/en/Content/ ArticleLanding/2019/ME/C8ME00060C. doi:10.1039/C8ME00060C

Patel, A., Loufakis, D., Flouda, P., George, I., Shelton, C., Harris, J., et al. (2020). Carbon Nanotube/Reduced Graphene Oxide/Aramid Nanofiber Structural Supercapacitors. ACS Appl. Energ. Mater. 3, 11763-11771. doi:10.1021/ acsaem.0c01926

Patel, A., Wilcox, K., Li, Z., George, I., Juneja, R., Lollar, C., et al. (2020). High Modulus, Thermally Stable, and Self-Extinguishing Aramid Nanofiber Separators. ACS Appl. Mater. Inter. 12, 25756-25766. doi:10.1021/ acsami.0c03671

Pereira, T., Guo, Z., Nieh, S., Arias, J., and Hahn, H. T. (2007). Embedding ThinFilm Lithium Energy Cells In Structural Composites. Compos. Sci. Technol. 68 (7-8), 1935-1941. doi:10.1016/j.compscitech.2008.02.019

Pereira, T., Guo, Z., Nieh, S., Arias, J., and Hahn, H. T. (2009). Energy Storage Structural Composites: a Review. J. Compos. Mater. 43, 549-560. doi:10.1177/ 0021998308097682

Poizot, P., Dolhem, F., and Gaubicher, J. (2018). Progress in All-Organic Rechargeable Batteries Using Cationic and Anionic Configurations: Toward Low-Cost and Greener Storage Solutions? Curr. Opin. Electrochemistry 9, 70-80. doi:10.1016/j.coelec.2018.04.003

Qian, H., Bismarck, A., Greenhalgh, E. S., Kalinka, G., and Shaffer, M. S. P. (2008). Hierarchical Composites Reinforced with Carbon Nanotube Grafted Fibers: 
The Potential Assessed at the Single Fiber Level. Chem. Mater. 20, 1862-1869. doi:10.1021/cm702782j

Qian, H., Diao, H., Shirshova, N., Greenhalgh, E. S., Steinke, J. G. H., Shaffer, M. S. P., et al. (2013). Activation of Structural Carbon Fibres for Potential Applications in Multifunctional Structural Supercapacitors. J. Colloid Interf. Sci. 395, 241-248. doi:10.1016/j.jcis.2012.12.015

Qian, H., Greenhalgh, E. S., Shaffer, M. S. P., and Bismarck, A. (2010). Carbon Nanotube-Based Hierarchical Composites: A Review. J. Mater. Chem. 20, 4751-4762. doi:10.1039/c000041h

Qian, H., Kucernak, A. R., Greenhalgh, E. S., Bismarck, A., and Shaffer, M. S. P. (2013). Multifunctional Structural Supercapacitor Composites Based on Carbon Aerogel Modified High Performance Carbon Fiber Fabric. ACS Appl. Mater. Inter. 5, 6113-6122. doi:10.1021/am400947j

Rana, M., Boaretto, N., Mikhalchan, A., Vila Santos, M., Marcilla, R., and Vilatela, J. J. (2021). Composite Fabrics of Conformal MoS2 Grown on CNT Fibers: Tough Battery Anodes without Metals or Binders. ACS Appl. Energ. Mater. 4, 5668-5676. doi:10.1021/acsaem.1c00482

Rana, M., Ou, Y., Meng, C., Sket, F., González, C., and Vilatela, J. J. (2020). Damage-Tolerant, Laminated Structural Supercapacitor Composites Enabled by Integration of Carbon Nanotube Fibres. Multifunct. Mater. 3, 015001. doi:10.1088/2399-7532/ab686d

Reece, R., Lekakou, C., and Smith, P. A. (2020). A High-Performance Structural Supercapacitor. ACS Appl. Mater. Inter. 12, 25683-25692. Available at: https://pubs.acs.org/doi/10.1021/acsami.9b23427. doi:10.1021/acsami.9b23427

Reece, R., Lekakou, C., and Smith, P. A. (2019). A Structural Supercapacitor Based on Activated Carbon Fabric and a Solid Electrolyte. Mater. Sci. Tech. 35, 368-375. doi:10.1080/02670836.2018.1560536

Roberts, S. C., and Aglietti, G. S. (2010). Structural Performance of a Multifunctional Spacecraft Structure Based on Plastic Lithium-Ion Batteries. Acta Astronautica 67, 424-439. doi:10.1016/j.actaastro.2010.03.004

Sánchez-Romate, X. F., Bosque, A. D., Artigas-Arnaudas, J., Muñoz, B. K., Sánchez, M., and Ureña, A. (2021). A Proof of Concept of a Structural Supercapacitor Made of Graphene Coated Woven Carbon Fibers: EIS Study and Mechanical Performance. Electrochimica Acta 370, 137746. doi:10.1016/ j.electacta.2021.137746

Schneider, L. M., Ihrner, N., Zenkert, D., and Johansson, M. (2019). Bicontinuous Electrolytes via Thermally Initiated Polymerization for Structural Lithium Ion Batteries. ACS Appl. Energ. Mater. 2 (6), 4362-4369. Available at: http://pubs. acs.org/doi/10.1021/acsaem.9b00563. doi:10.1021/acsaem.9b00563

Senokos, E., Ou, Y., Torres, J. J., Sket, F., González, C., Marcilla, R., et al. (2018). Energy Storage in Structural Composites by Introducing CNT Fiber/polymer Electrolyte Interleaves. Sci. Rep. 8, 1-10. doi:10.1038/s41598-018-21829-5

Senokos, E., Rana, M., Vila, M., Fernandez-Cestau, J., Costa, R. D., Marcilla, R., et al. (2020). Transparent and Flexible High-Power Supercapacitors Based on Carbon Nanotube Fibre Aerogels. Nanoscale 12, 16980-16986. doi:10.1039/ d0nr04646a

Senokos, E., Reguero, V., Cabana, L., Palma, J., Marcilla, R., and Vilatela, J. J. (2017). Large-Area, All-Solid, and Flexible Electric Double Layer Capacitors Based on CNT Fiber Electrodes and Polymer Electrolytes. Adv. Mater. Technol. 2 (7), 1600290. doi:10.1002/admt.201600290

Senokos, E., Reguero, V., Palma, J., Vilatela, J. J., and Marcilla, R. (2016). Macroscopic Fibres of CNTs as Electrodes for Multifunctional Electric Double Layer Capacitors: from Quantum Capacitance to Device Performance. Nanoscale 8, 3620-3628. doi:10.1039/c5nr07697h

Sha, Z., Huang, F., Zhou, Y., Zhang, J., Wu, S., Chen, J., et al. (2021). Synergies of Vertical Graphene and Manganese Dioxide in Enhancing the Energy Density of Carbon Fibre-Based Structural Supercapacitors. Composites Sci. Tech. 201, 108568. doi:10.1016/j.compscitech.2020.108568

Shen, Z., and Zhou, H. (2017). Mechanical and Electrical Behavior of Carbon Fiber Structural Capacitors: Effects of Delamination and Interlaminar Damage. Compos. Structures 166, 38-48. doi:10.1016/j.compstruct.2016.12.062

Shi, K., Yang, X., Cranston, E. D., and Zhitomirsky, I. (2016). Efficient Lightweight Supercapacitor with Compression Stability. Adv. Funct. Mater. 26, 6437-6445. doi:10.1002/adfm.201602103

Shirshova, N., Bismarck, A., Carreyette, S., Fontana, Q. P. V., Greenhalgh, E. S., Jacobsson, P., et al. (2013). Structural Supercapacitor Electrolytes Based on Bicontinuous Ionic Liquid-Epoxy Resin Systems. J. Mater. Chem. A. 1, 15300,
2013 . Available at: http://xlink.rsc.org/?DOI=c3ta13163g. doi:10.1039/ c3ta13163g

Shirshova, N., Qian, H., Houllé, M., Steinke, J. H. G., Kucernak, A. R. J., Fontana, Q. P. V., et al. (2014). Multifunctional Structural Energy Storage Composite Supercapacitors. Faraday Discuss. 172, 81-103. doi:10.1039/c4fd00055b

Shirshova, N., Qian, H., Shaffer, M. S. P., Steinke, J. H. G., Greenhalgh, E. S., Curtis, P. T., et al. (2013). Structural Composite Supercapacitors. Composites Part A: Appl. Sci. Manufacturing 46, 96-107. doi:10.1016/j.compositesa.2012.10.007

Snyder, J. F., Carter, R. H., Wong, E. L., Nguyen, P. A., Ngo, E. H., and Wetzel, E. D. (2006). "Multifunctional Structural Composite Batteries" in Proceedings From SAMPE 06 Fall Technical Conference, Dallas, TX.

Snyder, J. F., Carter, R. H., Wong, E. L., Nguyen, P. A., Xu, K., Ngo, E. H., et al. (2006). Int. SAMPE Tech. Conf., 1-13.

Snyder, J. F., O’Brien, D. J., and Wetzel, E. D. (2015). "Structural Batteries, Capacitors and Supercapacitors," in Handbook of Solid State Batteries. Editors N. J. Dudney, W. C. West, and J. Nanda (Singapore: World Scientific), 657-699. Available at: http://www.worldscientific.com/doi/abs/10. 1142/9789814651905_0019. doi:10.1142/9789814651905_0019

Subhani, K., Jin, X., Mahon, P. J., Kin Tak Lau, A., and Salim, N. V. (2021). Graphene Aerogel Modified Carbon Fiber Reinforced Composite Structural Supercapacitors. Composites Commun. 24, 100663. doi:10.1016/ j.coco.2021.100663

Sun, J., Gargitter, V., Pei, S., Wang, T., Yan, Y., Advani, S. G., et al. (2020). Mechanical and Electrochemical Performance of Hybrid Laminated Structural Composites with Carbon Fiber/Solid Electrolyte Supercapacitor Interleaves. Composites Sci. Tech. 196, 108234. doi:10.1016/j.compscitech.2020.108234

Carlson, T. (2013). Multifunctional Composite Materials: Design, Manufacture And Experimental Characterisation. Thesis: Doctoral dissertation Lulea University of Technology.

Thakur, A., and Dong, X. (2020). Additive Manufacturing of 3D Structural Battery Composites with Coextrusion Deposition of Continuous Carbon Fibers. Manufacturing Lett. 26, 42-47. doi:10.1016/j.mfglet.2020.09.007

Thomas, J., Qidwai, S., Pogue, W., and Pham, G. (2013). Multifunctional StructureBattery Composites for marine Systems. J. Compos. Mater. 47, 5-26. doi:10.1177/0021998312460262

Westover, A. S., Tian, J. W., Bernath, S., Oakes, L., Edwards, R., Shabab, F. N., et al. (2014). A Multifunctional Load-Bearing Solid-State Supercapacitor. Nano Lett. 14, 3197-3202. doi:10.1021/nl500531r

Wong, E. L., Baechle, D. M., Xu, K., Carter, R. H., Snyder, J. F., and Wetzel, E. D. (2007). Design and Processing of Structural Composite Batteries.

Wu, F., and Yushin, G. (2017). Conversion Cathodes for Rechargeable Lithium and Lithium-Ion Batteries. Energy Environ. Sci. 10, 435-459. doi:10.1039/ c6ee02326f

Xu, J., Johannisson, W., Johansen, M., Liu, F., Zenkert, D., Lindbergh, G., et al. (2020). Characterization of the Adhesive Properties between Structural Battery Electrolytes and Carbon Fibers. Composites Sci. Tech. 188, 107962, 2020. Available at: https://linkinghub.elsevier.com/retrieve/pii/S0266353819326879. doi:10.1016/j.compscitech.2019.107962

Xu, J., Lindbergh, G., and Varna, J. (2018). Carbon Fiber Composites with Battery Function: Stresses and Dimensional Changes Due to Li-Ion Diffusion. J. Compos. Mater. 52, 2729-2742. doi:10.1177/0021998317752825

$\mathrm{Xu}$, J., and Zhang, D. (2017). Multifunctional Structural Supercapacitor Based on Graphene and Geopolymer. Electrochimica Acta 224, 105-112. doi:10.1016/ j.electacta.2016.12.045

Xu, Y., Pei, S., Yan, Y., Wang, L., Xu, G., Yarlagadda, S., et al. (2021). HighPerformance Structural Supercapacitors Based on Aligned Discontinuous Carbon Fiber Electrodes and Solid Polymer Electrolytes. ACS Appl. Mater. Inter. 13, 11774-11782. doi:10.1021/acsami.0c19550

Yan, J., Ren, C. E., Maleski, K., Hatter, C. B., Anasori, B., Urbankowski, P., et al. (2017). Flexible MXene/Graphene Films for Ultrafast Supercapacitors with Outstanding Volumetric Capacitance. Adv. Funct. Mater. 27, 1701264, 2017. Available at: http://doi.wiley.com/10.1002/adfm.201701264. doi:10.1002/ adfm.201701264

Yu, Y., Zhang, B., Feng, M., Qi, G., Tian, F., Feng, Q., et al. (2017). Multifunctional Structural Lithium Ion Batteries Based on Carbon Fiber Reinforced Plastic Composites. Composites Sci. Tech. 147, 62-70. doi:10.1016/ j.compscitech.2017.04.031 
Zeng, L., Li, P., Yao, Y., Niu, B., Niu, S., and Xu, B. (2020). Recent Progresses of 3D Printing Technologies for Structural Energy Storage Devices. Mater. Today Nano 12, 100094. doi:10.1016/j.mtnano.2020.100094

Zhang, C. J., Anasori, B., Seral-Ascaso, A., Park, S.-H., McEvoy, N., Shmeliov, A., et al. (2017). Transparent, Flexible, and Conductive 2D Titanium Carbide (MXene) Films with High Volumetric Capacitance. Adv. Mater. 29, 1702678, 2017 . Available at: http://doi.wiley.com/10.1002/adma.201702678. doi:10.1002/adma.201702678

Zhang, W.-J. (2011). Structure and Performance of LiFePO4 Cathode Materials: A Review. J. Power Sourc. 196, 2962-2970. doi:10.1016/j.jpowsour.2010.11.113

Zhao, M.-Q., Ren, C. E., Ling, Z., Lukatskaya, M. R., Zhang, C., Van Aken, K. L., et al. (2015). Flexible MXene/Carbon Nanotube Composite Paper with High Volumetric Capacitance. Adv. Mater. 27, 339-345. Available at: http://doi. wiley.com/10.1002/adma.201404140. doi:10.1002/adma.201404140

Zheng, S., Zhang, C., Zhou, F., Dong, Y., Shi, X., Nicolosi, V., et al. (2019). Ionic Liquid Pre-intercalated MXene Films for Ionogel-Based Flexible Microsupercapacitors with High Volumetric Energy Density. J. Mater. Chem. A. 7, 9478-9485. doi:10.1039/c9ta02190f
Conflict of Interest: The authors declare that the research was conducted in the absence of any commercial or financial relationships that could be construed as a potential conflict of interest.

Publisher's Note: All claims expressed in this article are solely those of the authors and do not necessarily represent those of their affiliated organizations, or those of the publisher, the editors and the reviewers. Any product that may be evaluated in this article, or claim that may be made by its manufacturer, is not guaranteed or endorsed by the publisher.

Copyright (c) 2022 Navarro-Suárez and Shaffer. This is an open-access article distributed under the terms of the Creative Commons Attribution License (CC $B Y$ ). The use, distribution or reproduction in other forums is permitted, provided the original author(s) and the copyright owner(s) are credited and that the original publication in this journal is cited, in accordance with accepted academic practice. No use, distribution or reproduction is permitted which does not comply with these terms. 